\title{
ACUTE FULMINATING PUERPERAL MYOCARDITIS
}

\author{
BY \\ A. A. FARUQUE \\ From the Department of Pathology, General Hospital, West Hartlepool, Durham
}

Puerperal myocarditis is a rare condition to which attention was first drawn by Gouley, McMillan, and Bellet (1937). Subsequently more cases were reported, mostly from America; there are reports of 4 cases from this country: 3 by Brigden (1957), and 1 by Rosen (1959). The condition shows a uniform clinical and pathological picture, characterized by congestive cardiac failure in the third trimester of pregnancy or more commonly the puerperium, with degeneration and fibrosis of the myocardium. A review of unusual cardiac deaths that came to necropsy in this department revealed an interesting case in a woman of 24 years who died of acute pulmonary odema six days after childbirth, and 32 hours after the onset of symptoms. She was found to have a florid acute myocarditis. The case is unusual in that the clinical and histological pictures are quite different from those described for the post-partum myocardial disease, and also in that an acute myocarditis could produce a clinical picture resembling coronary artery disease or pulmonary embolism, but showing non-specific electrocardiographic changes of gross myocardial damage.

\section{Case Report}

Mrs. J. M., aged 24, was admitted to hospital in the evening of August 1, 1959, with a history of sudden onset of severe pain behind the sternum, sweating, and feeling faint. On July 27 she had delivered a full-term living child normally at her home. The pregnancy, labour, and the immediate post-partum period were all normal; there was no post-partum hæmorrhage. There was no history of previous illness, chest pain, or symptoms of indigestion. Her two previous pregnancies and deliveries were also essentially normal. On admission, the patient was pale, sweating, and somewhat shocked; her pulse was 94 a minute, respiration 28 a minute, and temperature $99^{\circ} \mathrm{F}$. $\left(37 \cdot 2^{\circ} \mathrm{C}\right.$.). The blood pressure was $90 / 70 \mathrm{~mm}$. Hg. Examination of the cardiovascular and respiratory systems did not show any abnormal features at this time. Vaginal examination showed the uterus of about eight weeks' size with os open. A tentative diagnosis of pulmonary embolism was made though no apparent source of embolus was detected; Homan's sign was negative. The patient was treated with morphine and anticoagulants. She seemed to respond well, and had a comfortable night. In the morning, however, her condition worsened suddenly, and she developed severe bilateral pulmonary odema. No cause for this sudden left ventricular failure could be found. Her treatment now consisted of morphine, digitalis, mersalyl, and oxygen. An electrocardiogram taken later in the day showed numerous abnormalities consisting of pathological Q waves, $T$ waves inversion, and abnormalities of S-T segments, which were non-specific but suggested gross myocardial damage (Fig. 1). Puerperal myocarditis was

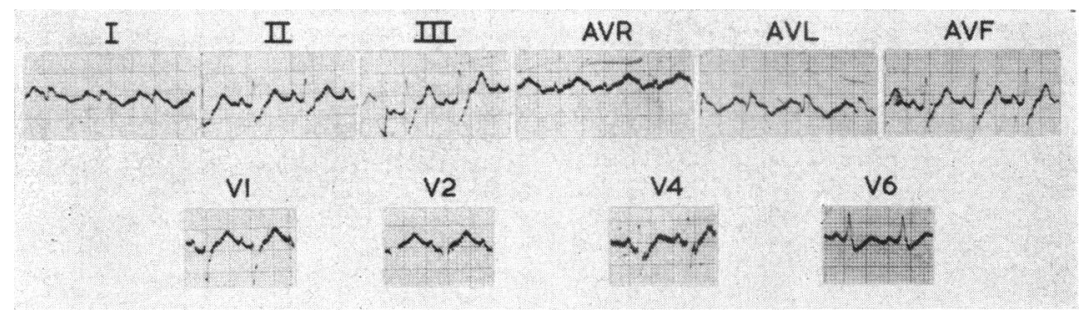

FIG. 1.-Electrocardiogram: Low voltage, rate 124 per minute, sinus rhythm. $Q$ waves in leads $I$ and $\mathrm{aVL}$, and slurring of the $R$ complexes in most of the leads. S-T elevation in lead $I$, and $S-T$ depression in V4 and V6. T wave inversion in leads I and aVL. The findings are non-specific but suggest gross myocardial damage. 


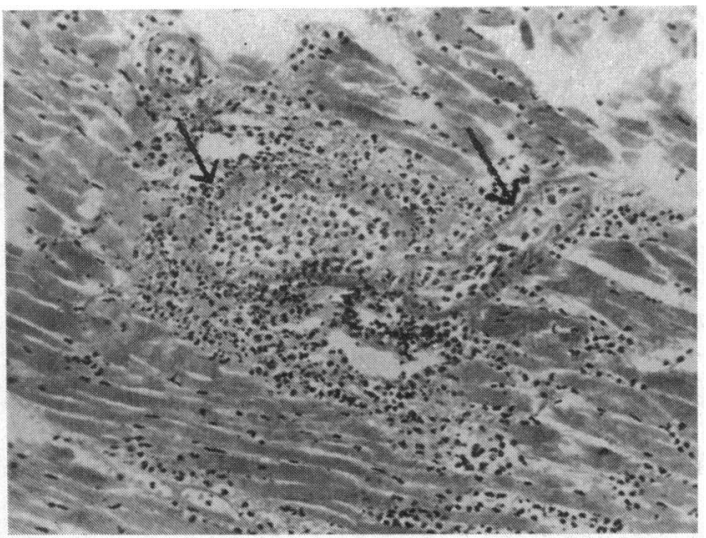

FIG. 2 (A).-Section from left ventricle showing hæmorrhage and dense polymorphonuclear infiltration; two small arteries show fibrinoid necrosis of their walls (arrows). (H. and E., $\times 115$.)

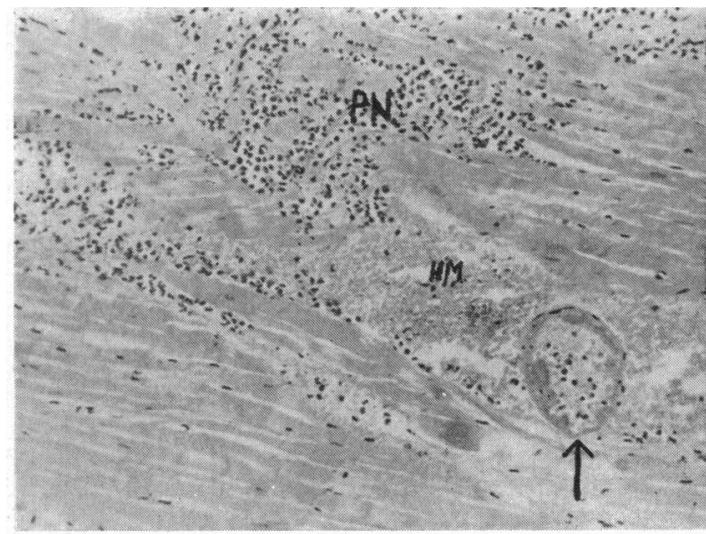

Fig. 2(B).-Left ventricle shows necrosis of some muscle fibres (at lower left-hand), hæmorrhage (HM), polymorphonuclear infiltration (PN), and a necrotic artery (arrow). (H. and E., $\times 80)$.

suggested, and treatment with antibiotics was started. There was no response to the treatment, her condition deteriorated rapidly with increasing pulmonary œdema, and she died the same night.

Necropsy. About $1 \mathrm{oz}$. of fluid was present in the right pleural cavity and less in the left. The lungs (right $850 \mathrm{~g}$., left $580 \mathrm{~g}$.) were congested and very œdematous with frothing in the bronchi. No pulmonary embolus was found. The heart $(370 \mathrm{~g}$.) showed numerous small but vivid areas of subepicardial hæmorrhage of irregular shape over much of the front and left side of the left ventricle. On incising the heart, deep congestion with yellow areas mimicking confluent infarct occupied the inner half of the whole thickness of the left ventricular wall from top to bottom, including the left half of the interventricular septum. The coronary arteries were normal and showed no atheroma or thrombosis. There was a small subintimal hremorrhage in the first half inch of the descending branch of the left coronary artery which slightly lifted the intima, but did not occlude the lumen. The liver $(1580 \mathrm{~g}$.) showed nutmeg pattern on a pale background. The kidneys (right $100 \mathrm{~g}$., left $110 \mathrm{~g}$.) were smooth, with cortex rather pale but of normal width. The spleen $(100 \mathrm{~g}$.) was soft; the adrenals, thyroid, and pancreas were all normal. The post-partum uterus appeared normal and contained adherent clots.

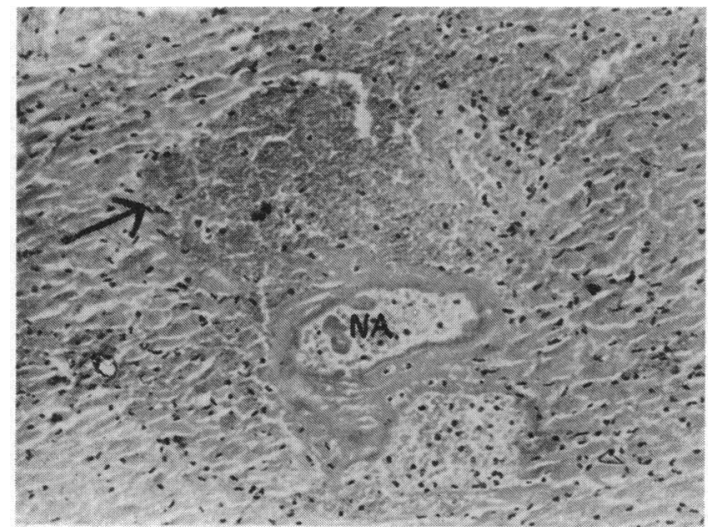

FIG. 3(A).--Interventricular septum shows a large area of hæmorrhage (arrow), a necrotic artery (NA), and scattered polymorphonuclear infiltration. (H. and E., $\times 80$.)

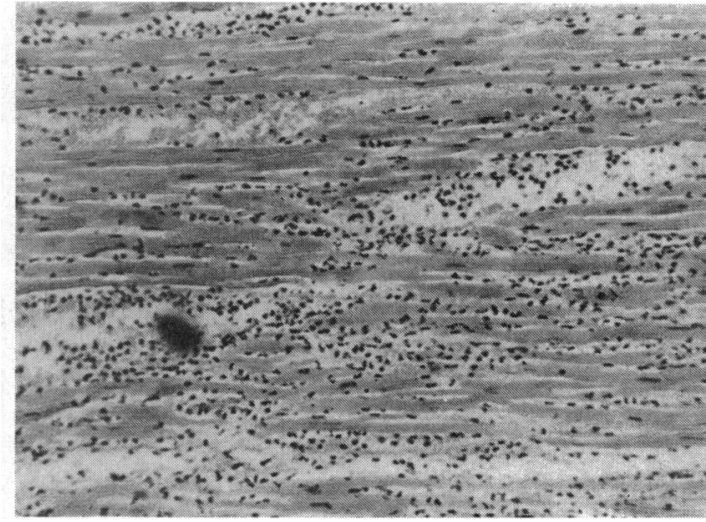

FIG. 3(B).-Section from interventricular septum shows dense polymorphonuclear infiltration. $(\mathrm{H}$. and E., $\times 80$.) 
Histology. The liver showed chronic venous congestion; the kidneys, thyroid, adrenals, and pituitary were all normal. Numerous blocks were sampled from different parts of the heart muscle which showed a picture of acute inflammatory reaction. The left ventricle (Fig. 2A and B) and the interventricular septum (Fig. 3A and B) were most severely affected with large hæmorrhages, and dense and widespread infiltration of polymorphonuclear leucocytes. The right atrium (Fig. 4) came next in severity, and then the right ventricle (Fig. 5), both of which showed scattered patchy polymorphonuclear infiltration and small hæmorrhages. The left atrium was the least severely involved part and showed only scattered polymorphonuclear infiltration. The small arteries showed fibrinoid necrosis of their walls, but these were mostly in the areas of inflammation. Considering the naked-eye appearance in the left ventricle and the interventricular septum, necrosis of the muscle was not extensive or widespread; sections from these parts showed isolated areas where individual muscle fibres showed loss of striations, with chromatolysis or pyknosis of the nuclei (Fig. 2B).

Sections from the heart muscle stained by Gram's method showed Gram-positive cocci, singly and in clumps, scattered in the muscle fibres.

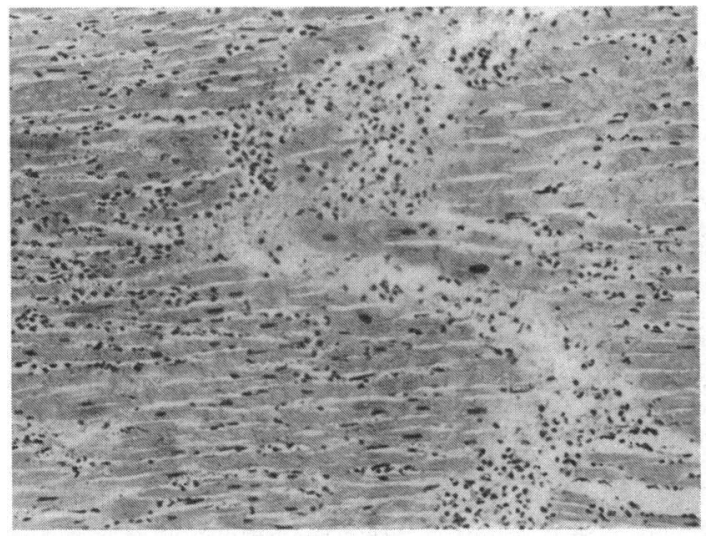

FIG. 4.-Section from right atrium shows hæmorrhage and polymorphonuclear infiltration. (H. and E., $\times 80$.)

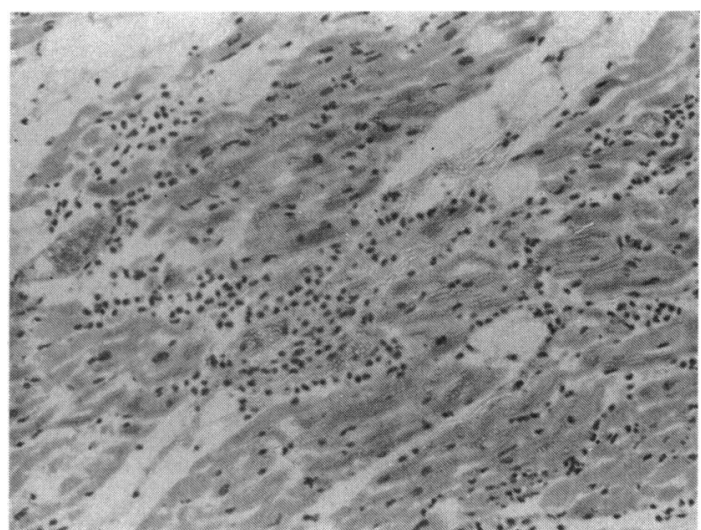

FIG. 5.-Section from right ventricle shows patchy scattered polymorphonuclear infiltration and small hæmorrhages. (H. and E., $\times 80$.)

\section{Discussion}

Myocardial disease occurring in late pregnancy or the puerperium has been found to show a uniform clinical picture which has been summarized by Meadows (1957). Patients usually develop congestive cardiac failure quickly, and this may continue for weeks or months. Often there is chest or abdominal pain. The electrocardiogram regularly shows $\mathrm{T}$ wave inversion in multiple limb and præcordial leads, but significant $Q$ wave or conduction defects are not seen. The heart is usually enlarged, and formation of mural thrombi is common, producing both pulmonary and systemic embolism which has been the cause of death in the few reported fatal cases. In general, the prognosis is good; most patients recover completely. Pathologically, the condition is described as degenerative rather than inflammatory in nature. The myocardium shows foci of degeneration, fibrosis, hæmorrhage, and a cellular infiltration consisting of minimal to moderate numbers of lymphocytes, and macrophages with an occasional polymorphonuclear leucocyte. The clinical and histological pictures in the present case could lead to the suspicion of an acute myocardial infarction. However, against this diagnosis are the age of the patient, the absence of any previous history of angina or other symptoms suggesting coronary insufficiency, the non-specific and widespread electrocardiographic changes, the histological evidence of cellular infiltration in all parts of the heart, and the absence of coronary atheroma or thrombosis. The subintimal hæmorrhage in the descend- 
ing branch of the left coronary artery, in this case, is secondary to massive inflammation and hæmorrhage in the heart muscle, which also showed many other hæmorrhagic foci and fibrinoid necrosis of small arteries and arterioles. It seems hardly possible that the subintimal hæmorrhage in one of the coronary arteries which only partially lifted the intima without causing any occlusion of the lumen could have produced such a stormy reaction, both clinically and pathologically. In cases of absent thrombi in myocardial infarction, the intimal hæmorrhage occurs in an atheromatous plaque (Boyd, 1958). The coronary arteries in the present case were free of atheroma or thrombosis. Also necrosis of the muscle was not extensive or widespread as one would have expected in a case of infarction.

The cause of post-partum heart disease is not known, but Benchimol, Dias Carneiro, and Schlesinger (1959), in a study of 18 cases from Brazil, suggested five causes: (1) definite toxæmia of pregnancy, (2) probable toxæmia of pregnancy, (3) non-specific infection, (4) specific infection, such as tuberculosis or trypanosomiasis, and (5) pre-existing heart or renal disease. The present case belongs to Group 3. The two patients in this group described by Benchimol et al. exhibited fever and a rapid erythrocytic sedimentation rate, but no infective organisms were isolated. Both recovered.

Cases of acute myocarditis have been found to occur in association with most infectious diseases (Gore and Saphir, 1947), but most are self-limited and remain unrecognized clinically. Gydell, Biörck, and Winblad (1955) reported 8 cases of acute fatal myocarditis in which the histological changes were of non-specific inflammatory type with predominantly polymorphonuclear infiltration. The clinical course in these cases was of much less dramatic nature than the present case, and in none were abnormal $Q$ waves present in the electrocardiogram. Karni (1954) reported eight cases of sudden death due to myocarditis, but pathological examination of the heart muscles in all revealed a chronic process, characterized by degeneration, fibrosis, and a very slight cellular infiltration consisting mainly of round cells. Unfortunately, because of the primary diagnosis of pulmonary embolism, and the very short period of illness in the present case, no evidence of infection was demonstrated by laboratory methods during life. Infection was suggested by her confinement outside hospital, and at necropsy by the soft spleen, and finally by demonstrating organisms in sections of the heart muscle. The interesting point is that while showing a severe infection of the myocardium, there were no clinical features to suggest a septicæmia; the temperature was only slightly raised, but this could be explained by the presence of overwhelming infection and some "shock". It seems quite possible that some, if not most, cases of post-partum heart disease begin as acute myocarditis which may or may not produce symptoms before progressing to the stage of degeneration and fibrosis of the myocardium, and congestive heart failure. In 73 per cent of patients in Meadows' (1957) series the onset of symptoms was by the end of seventh post-partum week: this might suggest the probability of a subclinical acute infection of the myocardium in the early part of the puerperium. The post-mortem finding of degeneration and fibrosis of the myocardium in the small number of fatal cases could be explained by the fact that by the time these patients died after months of illness the cardiac lesion was old and chronic.

\section{Summary}

A case of fatal acute myocarditis in a young adult woman following delivery is described with necropsy findings. The patient presented with severe retrosternal pain and soon developed severe pulmonary œdema which was rapidly fatal. Histological examination showed an acute inflammatory reaction with hæmorrhage and polymorphonuclear infiltration throughout the myocardium. The purpose of this paper is to point out the unusual clinical features, course, and pathological lesion of post-partum myocarditis with its obvious therapeutic implications. It is also of interest to note that an acute myocarditis produced a clinical picture resembling coronary artery disease or more remotely, pulmonary embolism, but produced non-specific electrocardiographic changes of gross myocardial damage. 
I wish to thank Mr. L. A. Cruttenden, Consultant Obstetrician, for permission to present this case; Dr. R. T. Cooke, who performed the post-mortem examination, and Dr. C. L. Grant, for their help and comments on this paper; and Dr. N. Conley and Mr. A. E. Brown for the photographs.

\section{References}

Benchimol, A. B., Dias Carneiro, R., and Schlesinger, P. (1959). Post-partum heart disease. Brit. Heart J., $21,89$. Boyd, W. (1958). Pathology for the Physician, 6th ed., p. 47. Lea and Febiger, Philadelphia.

Brigden, W. (1957). Uncommon myocardial diseases; the non-coronary cardiomyopathies. Lancet, $2,1179$.

Gore, I., and Saphir, O. (1947). Myocarditis-a classification of 1402 cases. Amer. Heart J., 34, 827.

Gouley, B. A., McMillan, T. M., and Bellet, S. (1937). Idiopathic myocardial degeneration associated with pregnancy and especially the puerperium. Amer. J. med. Sci., 194, 185.

Gydell, K., Biörck, G., and Winblad, S. (1955). Acute, fatal myocarditis. Acta med. scand., $151,1$.

Karni, H. (1954). Sudden death due to myocarditis. Acta med. scand., 149, 243.

Meadows, W. R. (1957). Idiopathic myocardial failure in the last trimester of pregnancy and the puerperium. Circulation, 15, 903.

Rosen, S. M. (1959). Puerperal cardiomyopathy. Brit. med. J., 2, 5. 